\title{
Biochemical markers in vascular cognitive impairment associated with subcortical small vessel disease - A consensus report
}

\author{
A. Wallin ${ }^{1,18^{*}}$ (D, E. Kapaki ${ }^{2}$, M. Boban ${ }^{3}$, S. Engelborghs ${ }^{4,5}$, D. M. Hermann ${ }^{6}$, B. Huisa ${ }^{7}$, M. Jonsson ${ }^{1}$, M. G. Kramberger ${ }^{8}$, \\ L. Lossi ${ }^{9}$, B. Malojcic ${ }^{3}$, S. Mehrabian ${ }^{10}$, A. Merighi ${ }^{9}$, E. B. Mukaetova-Ladinska ${ }^{11}$, G. P. Paraskevas ${ }^{2}$, B. O. Popescu ${ }^{12}$, \\ R. Ravid ${ }^{13}$, L. Traykov ${ }^{10}$, G. Tsivgoulis ${ }^{14}$, G. Weinstein ${ }^{15}$, A. Korczyn ${ }^{16}$, M. Bjerke ${ }^{5}$ and G. Rosenberg ${ }^{17}$
}

\begin{abstract}
Background: Vascular cognitive impairment (VCl) is a heterogeneous entity with multiple aetiologies, all linked to underlying vascular disease. Among these, $\mathrm{VCl}$ related to subcortical small vessel disease (SSVD) is emerging as a major homogeneous subtype. Its progressive course raises the need for biomarker identification and/or development for adequate therapeutic interventions to be tested. In order to shed light in the current status on biochemical markers for VCI-SSVD, experts in field reviewed the recent evidence and literature data.

Method: The group conducted a comprehensive search on Medline, PubMed and Embase databases for studies published until 15.01.2017. The proposal on current status of biochemical markers in VCI-SSVD was reviewed by all co-authors and the draft was repeatedly circulated and discussed before it was finalized.

Results: This review identifies a large number of biochemical markers derived from CSF and blood. There is a considerable overlap of VCI-SSVD clinical symptoms with those of Alzheimer's disease (AD). Although most of the published studies are small and their findings remain to be replicated in larger cohorts, several biomarkers have shown promise in separating VCI-SSVD from AD. These promising biomarkers are closely linked to underlying SSVD pathophysiology, namely disruption of blood-CSF and blood-brain barriers (BCB-BBB) and breakdown of white matter myelinated fibres and extracellular matrix, as well as blood and brain inflammation. The leading biomarker candidates are: elevated CSF/blood albumin ratio, which reflects BCB/BBB disruption; altered CSF matrix metalloproteinases, reflecting extracellular matrix breakdown; CSF neurofilment as a marker of axonal damage, and possibly blood inflammatory cytokines and adhesion molecules. The suggested SSVD biomarker deviations contrasts the characteristic CSF profile in AD, i.e. depletion of amyloid beta peptide and increased phosphorylated and total tau.
\end{abstract}

Conclusions: Combining SSVD and AD biomarkers may provide a powerful tool to identify with greater precision appropriate patients for clinical trials of more homogeneous dementia populations. Thereby, biomarkers might promote therapeutic progress not only in VCI-SSVD, but also in AD.

Keywords: Vascular cognitive impairment, Subcortical small vessel disease, Biomarkers, Blood, CSF, Alzheimer's disease, Mixed type dementia, Dementia

\footnotetext{
*Correspondence: anders.wallin@neuro.gu.se

'Department of Psychiatry and Neurochemistry, Institute of Neuroscience and Physiology, Sahlgrenska Academy at the University of Gothenburg, Mölndal, Sweden

${ }^{18}$ Memory Clinic at Department of Neuropsychiatry, Sahlgrenska University Hospital, Institute of Neuroscience and Physiology at Sahlgrenska Academy, University of Gothenburg, Wallinsgatan 6, SE-431 41 Mölndal, Sweden Full list of author information is available at the end of the article
} 


\section{Background}

There are not yet efficient ways of treating or preventing dementia disorders of which Alzheimer's disease (AD) remains the most common target for therapeutic interventions. In contrast, only few clinical pharmacological trials have been conducted in subjects with vascular cognitive impairment (VCI). The lack of treatment success in VCI may be largely due to the heterogeneity of cerebrovascular diseases, with the majority of VCI clinical trials being performed in stroke patients. Only few clinical trials have been performed in patients with subcortical small vessel disease (SSVD), a common, fairly homogeneous, but often under-recognized type of VCI (VCI-SSVD) [1-4]. The clinical phenotype of combined $\mathrm{AD}$ and vascular pathologies is often referred to as mixed type dementia (MD). The overlap of SSVD, AD and normal aging makes the underlying clinical diagnosis challenging, and it may lead to misclassification of patients in treatment trials. One way of moving the field forward is to be more specific about disease definitions along the AD - SSVD axis. This, in turn, will allow for refinements of diagnostic criteria with more sharply defined patient cohorts.

\section{Method}

A focused meeting on VCI-SSVD biochemical markers was held as a part of the 9th International Congress on Vascular Dementia in Ljubljana, Slovenia, on 18 October, 2015. Experts in this field reviewed the current evidence and literature data. For the purpose of this narrative review, we conducted a comprehensive search on Medline, PubMed and Embase databases for studies published until 15.01.2017. The key words used in the current search were: subcortical small vessel disease, vascular dementia, vascular cognitive impairment, Alzheimer's disease, Binswanger's disease, biomarker(s), cerebrospinal fluid, blood, serum, plasma, blood brain barrier, white matter, genetics, tau protein(s), amyloid, inflammation. We critically reviewed all abstracts and obtained the full text of relevant papers. We grouped the identified relevant subcortical small vessel disease biomarkers into themes and report the major relevant findings. The proposal on current status of biochemical markers in VCI-SSVD was reviewed by the group, including additional experts who did not attend the meeting. The draft was repeatedly circulated and discussed before it was finalized.

\section{Types of cerebral small vessel diseases, other vascular} lesions and Alzheimer pathology

Cerebral SSVD refers to pathological processes affecting a spectrum of subcortical vascular changes visible on Computed Tomography/Magnetic Resonance Imaging (CT/MRI) as white matter lesions (WML), lacunes and cerebral microbleeds. Underlying vascular pathologies are arteriolosclerosis, lipohyalinosis, fibroid necrosis, oedema and damage to the blood-cerebrospinal fluid and blood-brain barriers $(\mathrm{BCB} / \mathrm{BBB})$, the latter resulting in chronic leakage of fluid and macromolecules in the white matter and inflammation (reviewed by Kalaria, 2016) [5]. Although SSVD pathogenesis remains poorly understood, it is an age-related condition, associated with a number of risk factors including systemic hypertension [6-9], chronic kidney disease [10, 11], smoking [12], metabolic syndrome [8, 13, 14], osteoporosis [15], chronic obstructive pulmonary disease [16] and sleepapnoea syndrome [17]. The SSVD clinical manifestations are largely due to complete (lacunes) or incomplete (WML) infarction(s) and microbleeds resulting in cognitive, motor and mood disturbances and eventually functional disability [2], although same lesions might appear in cognitively intact persons during normal ageing. In patients with hypertension and WML, cerebral blood flow autoregulation is restricted, resulting in lack of physiological vasodilation during times of increased oxygen and nutrient needs. This renders the brain vulnerable to ischemic hypoperfusion, particularly in the watershed regions of the white matter [18].

Clinico-pathological studies have associated the characteristic clinical symptoms of VCI-SSVD (i.e. presence of motor and executive slowing, forgetfulness and dysarthria) with the bidirectional disruption of pathways connecting the prefrontal cortex with the basal ganglia and thalamus [2]. As opposed to other vascular subtypes, VCI-SSVD patients presents with a slow progressive course, which may mimic $\mathrm{AD}$. On the other hand, late-onset $\mathrm{AD}$ patients frequently have significant SSVD burden, not necessarily related to their amyloid load [19]. The disruption of white matter network may be mediated via the effect of the small vessel pathology, rather than amyloid deposits [20]. A recent study showed age at onset as a crucial factor that determines distinct features in subcortical VCI patients, such as pathologic burden, structural changes and cognitive function. Early onset subcortical vascular cognitive impairment was reported to be associated with more lacunes, more severe frontal structural network disruption and more affected frontal executive functions. In contrast, later onset VCI-SSVD shows more pronounced amyloid burden, cortical and hippocampal atrophy [21]. The genetic component of VCI-SSVD is supported by the presence of monogenic forms representing a small portion of VCI-SSVD cases [22].

\section{Biochemical markers}

Although several studies using biochemical markers have been completed and reviewed in $\mathrm{AD}$, such information is still lacking for VCI-SSVD. Here we review studies using a broad range of biochemical markers from cerebrospinal fluid (CSF), plasma or serum in VCI-SSVD. 
Our primary question is whether they are useful to identify VCI-SSVD. We also review whether there are overlapping and differentiating findings between VCISSVD and AD.

\section{Blood-CSF/blood-brain barriers (BCB/BBB)}

The $\mathrm{BCB} / \mathrm{BBB}$ are highly selective permeability barriers that separate the circulating blood from the brain. The function and structure of $\mathrm{BCB} / \mathrm{BBB}$ alter with aging. Disruption of $\mathrm{BCB} / \mathrm{BBB}$ function, followed by blood-tobrain extravasation of circulating neuroinflammatory molecules, may increase the risk of brain injury. This may be an important factor for disease progression in both VCI and AD [23], and increasing evidence, also from pre-clinical translational studies, indicates that dysfunction of the $\mathrm{BCB} / \mathrm{BBB}$ may play a significant role in the pathogenesis of vascular dementia [24-26]. The $\mathrm{CSF} /$ serum albumin quotient (QA) is the gold-standard measure of $\mathrm{BCB} / \mathrm{BBB}$ integrity, with increases in this ratio indicating increased permeability. QA requires the measurement of albumin in CSF and serum collected concurrently [27, 28]. Advancing age is associated with increased $\mathrm{BCB} / \mathrm{BBB}$ permeability, which is further increased in patients with VCI (as compared to AD) and with worsening of WML [29]. Altered $\mathrm{BCB} / \mathrm{BBB}$ has consistently been reported in VCI-SSVD patients, and it is thought to contribute to the pathogenic process in AD [30-34].

Several lines of evidence suggested that the astrocytic protein $S 100 \beta$ is a potentially useful peripheral marker of $\mathrm{BCB} / \mathrm{BBB}$ permeability [35]. S100 $\beta$ can be released from injured astrocytes and enter the extracellular space and hence the bloodstream. This protein is elevated in radiologically defined SSVD [36, 37]. A positive correlation of $S 100 \beta$ levels with the severity of depression, a common symptom in SSVD, has also been reported [38]. Changes in $\mathrm{BCB} / \mathrm{BBB}$ function correlate strongly with an increase of two other proteins, namely glial fibrillary acidic protein (GFAP) and neuron specific enolase (NSE) in serum, indicating $\mathrm{BCB} / \mathrm{BBB}$ leakage [39]. However, they are both unspecific biological markers in dementia disorders [40-42].

\section{Inflammatory and glial activation markers}

Both the innate immune system and systematic inflammation have central roles in the pathophysiology of cognitive impairment $[43,44]$. While many molecules within the inflammatory pathway are likely to be involved, only few of them have been investigated in the context of VCI-SSVD.

$C$ reactive protein (CRP), a biomarker of systemic inflammation, is perhaps the most extensively studied circulatory biomarker of cerebral SSVD pathology. Although its association with SSVD (particularly in the presence of WML) is inconclusive [45-48], several studies have suggested that elevated peripheral CRP level increases the risk of VCI, but not $\mathrm{AD}[49,50]$. In addition, elevated serum CRP appears to be consistently associated with measures of white matter integrity [51, 52], whereas a rapid decline in CRP levels predicts a healthier white matter microstructure [53].

Interleukins (ILs) are a group of cytokines participating in the regulation of the immune response. A classification that proves useful in clinical practice (outside of structural biology) divides immunological cytokines into type 1 (IFN- $\gamma$, TNF $\alpha$, TNF $\beta$, IL-2, and IL-12-b), that enhances cellular immune responses and type 2 (TGF- $\beta$, IL-4, IL-5, IL-6, IL-10 and IL-13), which controls antibody responses. In the vasculature, interleukin-6 (IL-6) is secreted as a pro-inflammatory cytokine by tunica muscularis cells of the blood vessels. As a response to IL-6, the liver synthesizes the CRP. Although the majority of studies reported a positive association [54], the usefulness of IL- 6 and CRP as biomarkers of SSVD, particularly in the presence of WML, remains to be fully established [48]. In contrast, CSF TNF$\alpha$, TGF- $\beta$ and vascular endothelial growth factor (VEGF) levels are all elevated in VCI-SSVD patients [55, 56].

CSF $\alpha 1$-antichymotrypsin, an acute phase inflammatory protein, was also increased in individuals with VCISSVD compared to healthy controls as well as in prodromal VCI-SSVD patients who later progressed to dementia, whereas in AD it was elevated only in manifest dementia [57]. Interestingly, higher levels of serum $\alpha 1$-antichymotrypsin in individuals with $\mathrm{VCI}$, but not $\mathrm{AD}$, compared to controls have also been reported [58].

$Y K L-40$, a marker of glial activation, was elevated in CSF of patients with prodromal VCI but not prodromal AD [59].

\section{Markers of extracellular matrix breakdown}

Matrix metalloproteinases (MMPs) are a large family of enzymes active in the extracellular matrix, at the cell surface and intracellularly. Although there are 26 family members, MMP-2, $-3,-7,-9,-10$ and -12 are mainly active in the brain. Some MMPs, i.e. MMP-2, are constitutively produced and are normally present in the CSF. Others (mainly MMP-3 and MMP-9) are inducible with very low levels in the CSF until an inflammatory response is elicited [60,61]. Changes in several MMPs have been found in SSVD [33]. Measurement of MMPs and tissue inhibitor of metalloproteinases-1 (TIMP-1) are promising SSVD biomarkers, and have high validity in discriminating VCI-SSVD from cognitive impairment of primarily neurodegenerative etiology [33, 34, 57, 62, 63].

\section{Markers of subcortical neuronal degeneration and myelin damage Neurofilaments}

Neurofilaments (NFs) are major structural proteins of neurons. They consist of three subunits of low (NF-L), 
medium (NF-M), or high (NF-H) molecular weight with varying degrees of phosphorylation [64]. NFs may be sensitive surrogate markers for neuronal death and axonal loss [65]. Several early studies detected NF peptides in the CSF of several neurological/neurodegenerative disorders [66-69]. NF-L subunit is a protein expressed in large-caliber myelinated axons [70]. Slightly increased CSF NF-L levels occur in healthy older individuals and correlate with increasing age [66]. However, a more significant increase in CSF NF-L levels is also present in individuals with WML [32, 33, 71, 72]. A positive association of CSF-NF-L levels with increasing severity of WML in non-demented subjects has also been reported [73].

In acute cerebral infarction, very high NF-L levels were reported [66]. The CSF levels of NF-L were higher in dementia disorders engaging subcortical brain regions, such as VCI and MD, but also in fronto-temporal dementia (FTD) [74, 75]. In VCI-SSVD the CSF NF-L concentrations were consistently higher than in controls, however with considerable overlap among other dementia disorders $[32,72]$. In a recent meta-analysis comparing 106 VCI-SSVD patients with 283 healthy agematched controls, the patient group had increased CSF NF-L levels. However, the overall elevation was smaller than that for either AD or FTD patients versus controls [76].

Increased WML load and ventricular dilation were related to increased CSF levels of TIMP-1 and NF-L and to decreased SAPP $\beta$ (a marker of amyloid pathology), suggesting that these molecules may function as biological markers of white matter damage [77].

Far less is known about CSF levels of the other NF isoforms. One study reported increased CSF levels of phosphorylated NF-H/M in AD compared with VCI and controls [67]. Others have found elevated CSF NF-H levels in $\mathrm{AD}$ and $\mathrm{VCI}$ in comparison with controls, but no differences between FTD and controls, or between $\mathrm{AD}, \mathrm{VCI}$ and FTD patients [78].

\section{Myelin basic protein}

Myelin basic protein (MBP) is a major structural constituent of the myelin sheath [79]. Its function is to maintain the structure of the myelin and together with myelin-associated glycoprotein (MAG) to modulate the caliber of myelinated axons [80]. One of the hallmarks of VCI-SSVD is the rarefaction of white matter, due to nerve fiber degeneration, gliosis, demyelination or a combination of all three [81, 82]. Significantly elevated MBP CSF levels have been reported in stroke with subcortical infarcts affecting the white matter, as opposed to stroke with cortical infarcts [83], indicating its potential as a regional marker of infarction, as well as a marker of WML. Increased CSF levels of MBP and NF-L were found in acute ischemic stroke patients. In mild stroke $\{$ NIHSS $<5$ (National Institute of Health Stroke Scale)\}, the concentration of MBP was significantly lower compared to more severe stroke (NIHSS $>5$ ), while NF-L was a stronger marker for stroke in general, independent of severity [84]. Increased CSF levels of MBP and NF-L were also described in patients with WML as compared to controls. However, compared to controls, MBP and NF-L were increased in both VCI-SSVD and AD patients, with considerable overlap between patient groups [33].

\section{CSF sulfatide}

CSF sulfatide is an acidic glycophospholipid of oligodendrocyte-produced myelin sheaths considered as a marker of white matter degradation. It was found to be $200 \%$ higher in patients with VCI-SSVD compared to controls and patients with AD [85], while CSF sulfatide levels distinguished between patients with subcortical arteriosclerotic encephalopathy and those with normal pressure hydrocephalus with a sensitivity and specificity of 74 and $94 \%$ respectively [86]. CSF sulfatide has also been shown to predict WML progression in nondisabled patients with WML [87].

Furthermore, this marker was lower in mild cognitive impairment and mild AD compared to control subjects [88]. In another study TNF- $\alpha$ levels were significantly correlated with sulfatide levels [89], suggesting that this apoptosis-inducing cytokine may lead to oligodendrocytes death, thus contributing to white matter degeneration, a hallmark of SSVD.

\section{Markers of cortical neuronal degeneration Tau proteins}

Tau protein is the major component of intracellularly located neurofibrillary tangles and, in the neurofibrillary pathology, it is present in a hyperphosphorylated form. Both total and hyperphosphorylated tau have been found to be increased in the CSF of patients with AD [90]. Total tau (T-tau) is viewed as a marker of neuronal and/ or axonal degeneration, while hyperphosphorylated tau (P-tau) is a more specific marker of tangle formation in $\mathrm{AD}$ [91]. Although their diagnostic accuracy may be reduced to variable degree when attempting differentiating $\mathrm{AD}$ from other types of dementia, the above biomarkers, especially when combined with $A \beta 42$, achieve sensitivities and specificities $>90 \%$ for the discrimination of $\mathrm{AD}$ at least from normal ageing. They have now been incorporated in research guidelines for diagnosing incipient and manifest $\mathrm{AD}[92,93]$.

In VCI, CSF T-tau levels have been reported to be either normal [94-96], increased [97-101], or intermediate between those found in controls and $\mathrm{AD}$, but much lower as compared to those of AD [102, 103]. Even then, some patients with VCI do present with high or, 
sometimes, very high T-tau levels [96, 103-106]. When patients with VCI, MD or AD with WML were clinically separated, the results were again conflicting: T-tau in VCI was reported as comparable to controls [96], increased [101] or intermediate but much lower in comparison to those of $\mathrm{AD}$ [103], while patients with MD presented with increased T-tau in all studies. However, patients with lacunar infarcts [94], progressive WML [99] or VCI-SSVD (pure and/or combined with AD) $[32,33,107,108]$ had normal T-tau levels. The CSF levels of P-tau have been described as normal in VCI or VCI-SSVD [33, 100, 101, 103, 107, 108], while in MD, levels were increased to the level of AD [103] or intermediate between controls and AD [107].

\section{Markers of amyloid pathology $\beta$-amyloid}

Beta-amyloid peptides with 40 (A $\beta 40)$ and, especially, with 42 amino acids (A $\beta 42)$ are the major components of extracellular $\mathrm{AD}$ amyloid plaques. A 422 is considered to inversely reflect amyloid pathology, having high sensitivity and specificity (>85\%) as compared to cognitively intact old subjects and is now recognized as one of the three clinically useful CSF biomarkers (the other two being T-tau and P-tau) for AD [28, 91]. Reduction of CSF A $\beta 42$ in VCI of any type [106] and VCI-SSVD with or without signs of $\mathrm{AD}[33,72,108,109]$, at levels similar to $\mathrm{AD}$ or intermediate between controls and $\mathrm{AD}$ have been reported. In other studies, the levels of $A \beta 42$ in $\mathrm{VCI}$ were described as comparable to those of controls and higher than in $\operatorname{AD}[95,98,100,101,103]$, although overlap exists, with some VCI patients presenting with low levels [103]. Most of the above studies agreed that in $\mathrm{MD}, \mathrm{A} \beta 42$ levels were reduced in a degree comparable to $\mathrm{AD}$. However, the ratio of $\mathrm{A} \beta 42 / 40$, which is reduced in $\mathrm{AD}$, has been found to be comparable to controls in "pure" VCI [110].

\section{Amyloid precursor protein $\beta$}

Soluble amyloid precursor protein $\beta$ peptide $(\mathrm{sAPP} \beta)$ is a product of APP cleavage with potential neurotrophic properties on axons [111]. CSF sAPP $\beta$ has been shown to correlate with white matter lesion load in CSF [77] and seems to be unaltered in the CSF in AD patients [112].

\section{Markers of hypercoagulable state}

Several plasma markers of coagulation/fibrinolysis have been associated with VCI-SSVD [54]. The clotting cascade is regulated by balance of activators and inhibitors. Activators may be raised in hypercoagulable state either independently or in parallel with the lowering of inhibitors. The validation of candidate biomarkers is complicated by the existence of heterogeneity among cerebral vessels in different brain regions in response to coagulation dysfunction [113]. In addition, a tenable association with VCI-SSVD has often been difficult to demonstrate with certainty for most proposed markers [114]. Clinical observations have been strengthened, at least in part, by a recent demonstration of a number of downregulated coagulation-related genes in SSVD, after postmortem gene-expression microarray analysis [115].

\section{Markers of coagulation cascade}

Fibrinogen is the endpoint plasma protein of the clotting cascade. Conflicting results have been published regarding its possible significance as a biomarker in VCI-SSVD [116-122].

Factor VII (also known as serum prothrombin conversion accelerator) has been found increased [123], whereas antithrombin III, a plasma protein that inactivates thrombin, and $D$-dimer, a fibrin degradation product, were found to be reduced in VCI-SSVD [113, 114, 124].

\section{Markers derived from the endothelial cells, nearby tissue, or platelets}

Many studies report that numerous proteins expressed by the endothelial cells are positively associated with lacunar infarcts or WML and thus increased in VCI-SSVD because of endothelial damage [113, 123, 125-128]. There is a still growing list of these molecules, which includes: von Willebrand factor (vWF) [123]; thrombomodulin (CD141 or BDCA-3); the monokine induced by $\gamma$ interferon (MIG) or chemokine (C-X-C motif) ligand 9 (CXCL-9) [129]; soluble intercellular adhesion molecule1 (sICAM-1 also known as CD54); soluble vascular cell adhesion molecule-1 (sVCAM-1); and soluble E-selectin (sE-selectin), the two latter mediating the adhesion of white cells (except neutrophils) to the vascular endothelium [130-133]. However, other neuropathology studies did not confirm a local endothelial activation, and showed that the endothelial layer remains intact in VCISSVD [134, 135]. Specifically, the local expression of ICAM-1 and thrombomodulin in the vascular endothelium of small arteries was not confirmative of an association with VCI-SSVD [136]. Thus, the usefulness of these markers for diagnostic purposes remains to be established, as recently reviewed [137].

\section{Other neurotoxic/metabolic biomarkers}

Homocysteine (Hcy) is the metabolic product of dietary methionine. Hcy is also synthesized in the liver and kidney. Increased total Hcy plasma levels is associated with risk, clinical deterioration and severity of WML in symptomatic patients with SSVD [138, 139]. Still, the links between hyperhomocysteinemia and SSVD (including a possible endothelial mechanism) are poorly understood [138]. As recently reviewed, when Hcy plasma levels are below $100 \mu \mathrm{M}$ vascular effects are primarily seen, 
whereas adverse effects on the nerve cells appear, only when concentrations exceed $100 \mu \mathrm{M}$ (above clinicallyrelevant range) [140]. Still we are far from a full identification and characterization of the key molecular pathways linking Hcy to VCI-SSVD. However, preclinical and clinical data support the notion that Hcy is an important mediator of VCI-SSVD.

B-type natriuretic peptide (BNP, also referred to as ventricular natriuretic peptide) is a polypeptide secreted by heart ventricles in response to excessive stretching of cardiomyocytes. Similarly, cardiac troponin $\mathrm{T}$ is a very sensitive and specific indicator of myocardial damage. A few studies report that serum levels of BNP [141, 142] or cardiac troponin T [143] are elevated in VCI-SSVD. These results need to be substantiated by other investigations to propose these molecules as relevant biomarkers for VCI-SSVD.

\section{Oxidative stress markers}

Clinical studies on markers of oxidative stress in patients with VCI-SSVD and cognitive impairment are scarce. The Framingham study reported lower plasma levels of myeloperoxidase in participants with greater WML volumes and silent brain infarcts [47]. Asymmetric dimethylarginine (ADMA) is a key chemical involved in normal endothelial function and thus cardiovascular health. Higher plasma ADMA levels were associated with an increased prevalence of silent brain infarcts after adjustment for traditional stroke risk factors, indicating its potential usefulness as a new biomarker of subclinical vascular brain injury [144]. Patients with large-vessel disease had higher oxidative stress (as measured by the serum levels of thiobarbituric acid-reactive substances), but lower antioxidant defense (as measured by serum levels of free thiol) compared to those with SSVD after an acute ischemic stroke [145].

\section{Results and discussion Overlapping and differentiating biomarker findings in VCI-SSVD and AD}

Hitherto, there are no yet established biochemical markers for VCI-SSVD, although there are potential candidates. For AD, CSF T-tau, P-tau and A $\beta 42$ have been included in the diagnostic criteria by the National Institute on Aging and the Alzheimer's Association workgroup for all phases of AD, published in 2011 [92]. By analogy, in VCI-SSVD a major step forward will be to stratify biochemically homogenous patient groups. From the evidence presented in the current work, a significantly elevated albumin ratio reflecting $\mathrm{BCB} / \mathrm{BBB}$ dysfunction, a hallmark of VCI-SSVD, is a consistent finding in studies with VCI-SSVD and MD $[32,33,146,147]$. In $\mathrm{AD}$, the albumin ratio is not different from that of controls [33, 72, 147, 148].

Other promising biomarkers are those reflecting damage to the white matter, such as CSF NF-L and MBP. Both markers correlate with SSVD, but they have also been found to be elevated in AD. This overlap possibly reflects concomitant AD and SSVD pathology. However, both CSF NF-L and MBP can be of value in detecting damage to white matter in patients with VCI-SSVD or MD regardless of the white matter etiology. Markers, such as sulfatide, sAPP $\beta$, MMP-2, MMP-3, MMP-9 and TIMP-1, also hold potential for VCI-SSVD biomarkers, though some of them (MMP-2, MMP-3 and MMP-9) have also been described to be altered in $\mathrm{AD}[33,57,62,63,77,85-87,149,150]$. Other glial and neuronal markers, such as YKL-40, GFAP, S100B and NSE, are also related to AD and are thus not specific [41, 42, 151-153]. Markers of inflammation (i.e. IL-6, TNF- $\alpha$, TGF- $\beta$, VEGF, sICAM-1, sVCAM and sEselectin) have all been found to be increased in both diseases $[56,154,155]$. Other markers of questionable specificity for SSVD, as compared to AD, are CRP, ADMA and Hcy, since they have also been found to be elevated in $\mathrm{AD}[57,155]$. Biomarkers closely related to alterations of the vessel wall (vWF, thrombomodulin) and partakers in the coagulation/fibrinolysis system (D-dimer, Factor VII, antithrombin III), rather than inflammation in general, may prove to be more specific for VCI-SSVD and need to be investigated in the context of AD differential diagnosis. It should be noted that the overlap among the abovementioned biomarkers might be a result of heterogeneous $\mathrm{AD}$ populations containing $\mathrm{MD}$ patients emphasizing the need for further investigations of "pure" VCI-SSVD and $\mathrm{AD}$ cases.

At present, combination of markers reflecting SSVD with markers that seem to be more specific for AD pathology such as $A \beta 42$, T-tau and especially P-tau, appears promising for the exclusion of pure $\mathrm{AD}$ or favoring the diagnosis of MD [33].

\section{Are biomarkers useful for detection of $\mathrm{VCl}$-SSVD in clinical practice?}

Thus far, biochemical markers with potential benefit for the diagnosis of VCI-SSVD have limited use in every day clinical practice (see Table 1). Since combination of biomarkers increases accuracy of the AD diagnosis, it seems feasible that a multimodal biomarker approach may be beneficial for the diagnosis of VCI-SSVD as well. In the Ten Point Scale of Binswanger's disease (which is synonymous with VCI-SSVD), three axes of biomarkers are included: biochemical, imaging and clinical $[34,156]$. Increased albumin ratio, reduced MMP-2, elevated NF-L in the absence of a characteristic AD CSF profile are emphasized as the most significant among biochemical markers [34, 156]. Individuals with the highest scores, i.e. presence of the most of the aforementioned biomarkers, are most likely to have VCISSVD. Of course, this scoring system requires 
Table 1 Summary of studies on candidate CSF biomarkers for VaD, VCl and SSVD according to their discrimination power (vs. Controls and/or AD)

\begin{tabular}{|c|c|c|c|c|c|c|c|c|c|c|c|c|c|}
\hline $\begin{array}{l}\text { Candidate } \\
\text { biomarker }\end{array}$ & $\begin{array}{l}\text { Study } \\
\text { [Ref] }\end{array}$ & Date & Change & $\begin{array}{l}\mathrm{HC} \\
n\end{array}$ & $\begin{array}{l}\text { NC } \\
n\end{array}$ & $\begin{array}{l}\mathrm{VaD} \\
n\end{array}$ & $\begin{array}{l}\mathrm{VCl} \\
n\end{array}$ & $\begin{array}{l}\text { SSVD } \\
n\end{array}$ & $\begin{array}{l}\mathrm{AD} \\
n\end{array}$ & $\begin{array}{l}\text { Difference vs. } \\
\text { Controls }\end{array}$ & $\begin{array}{l}\text { Difference } \\
\text { vs. AD }\end{array}$ & $\begin{array}{l}\text { Sn/Sp vs. } \\
\text { Controls }\end{array}$ & $\begin{array}{l}S n / S p \\
\text { vs. AD }\end{array}$ \\
\hline \multirow{4}{*}{$\begin{array}{l}\text { Albumin ratio } \\
\text { (CSF/serum) }\end{array}$} & Wallin et al. [30] & 1990 & $\uparrow$ & 30 & - & 53 & - & - & - & $P<0.001$ & - & - & - \\
\hline & Bjerke et al [72] & 2009 & $\rightarrow$ & 52 & - & - & - & 9 & 20 & NS & NS & - & - \\
\hline & Bjerke et al. [33] & 2011 & $\uparrow$ & 30 & - & - & - & 26 & 30 & $P<0.005$ & $P<0.01$ & - & - \\
\hline & Wallin et al. [32] & 2001 & $\uparrow$ & 18 & - & - & - & 25 & - & $P<0.001$ & - & - & - \\
\hline NSE & Blennow et al. [41] & 1994 & $\uparrow$ & 33 & - & 19 & - & - & 45 & $P<0.0001$ & NS & - & - \\
\hline TNF-a & Tarkowski et al. [55] & 1999 & $\uparrow$ & 25 & - & 33 & - & - & 34 & $P<0.001$ & - & - & - \\
\hline VEGF & Tarkowski et al. [56] & 2002 & $\uparrow$ & 27 & - & 26 & - & - & 20 & $P=0.03$ & NS & - & - \\
\hline TGF-beta & Tarkowski et al. [56] & 2002 & $\uparrow$ & 27 & - & 26 & - & - & 20 & $P<0.0004$ & NS & - & - \\
\hline YKL-40 & Olsson et al. [59] & 2013 & $\uparrow$ & - & 65 & 19 & - & - & - & $P<0.05$ & - & - & - \\
\hline \multirow[t]{2}{*}{ MMP-9 } & Adair et al. [62] & 2004 & $\uparrow$ & 8 & - & 15 & - & - & 30 & $P<0.003$ & $P<0.0001$ & - & - \\
\hline & Bjerke et al. [33] & 2011 & $\uparrow$ & 30 & - & - & - & 26 & 30 & $P<0.05$ & $P<0.05$ & - & - \\
\hline MMP-10 & Bjerke et al. [33] & 2011 & $\uparrow$ & 30 & - & - & - & 26 & 30 & $P<0.005$ & NS & - & - \\
\hline MMP-2 & Bjerke et al. [33] & 2011 & $\rightarrow$ & 30 & - & - & - & 26 & 30 & NS & NS & - & - \\
\hline MMP-3 & Bjerke et al. [33] & 2011 & $\rightarrow$ & 30 & - & - & - & 26 & 30 & NS & NS & - & - \\
\hline \multirow[t]{3}{*}{ TIMP-1 } & Ohrfelt et al. [57] & 2011 & $\uparrow$ & 52 & - & - & - & 7 & 15 & $P=0.01$ & - & - & - \\
\hline & Ohrfelt et al. [57] & 2011 & $\uparrow$ & 52 & - & - & - & 8 & 24 & $P=0.03$ & - & - & - \\
\hline & Bjerke et al. [33] & 2011 & $\uparrow$ & 30 & - & - & - & 26 & 30 & $P<0.05$ & $P<0.005$ & - & - \\
\hline TIMP-2 & Bjerke et al. [33] & 2011 & $\rightarrow$ & 30 & - & - & - & 26 & 30 & NS & NS & - & - \\
\hline \multirow[t]{3}{*}{ NF-L } & Wallin et al. [32] & 2001 & $\uparrow$ & 18 & - & - & - & 25 & - & $P<0.001$ & - & $\begin{array}{l}\text { Sn } 68 \% \\
\text { Sp } 85 \%\end{array}$ & - \\
\hline & Bjerke et al. [72] & 2009 & $\uparrow$ & 52 & - & - & - & 9 & 20 & $P<0.001$ & NS & - & - \\
\hline & Bjerke et al. [33] & 2011 & $\uparrow$ & 30 & - & - & - & 26 & 30 & $P<0.0001$ & $P<0.05$ & - & - \\
\hline MBP & Bjerke et al. [33] & 2011 & $\uparrow$ & 30 & - & - & - & 26 & 30 & $P<0.0001$ & $P<0.005$ & - & - \\
\hline Sulfatide & Fredman et al. [85] & 1992 & $\uparrow$ & 19 & - & 20 & - & - & 43 & $P<0.0001$ & $P<0.0001$ & - & - \\
\hline \multirow[t]{4}{*}{ Total tau $\left(\tau_{T}\right)$} & Wallin et al. [32] & 2001 & $\rightarrow$ & 18 & - & - & - & 25 & - & NS & - & $\begin{array}{l}\text { Sn } 85 \% \\
\text { Sp 36\% }\end{array}$ & - \\
\hline & $\begin{array}{l}\text { Paraskevas et al. } \\
\text { [103] }\end{array}$ & 2009 & $\uparrow$ & 68 & ${ }_{-}^{-}$ & 23 & - & - & 92 & $P<0.05$ & $P<0.05$ & - & $\begin{array}{l}\text { Sn } 80 \% \\
\text { Sp } 86 \%\end{array}$ \\
\hline & Bjerke et al. [72] & 2009 & $\rightarrow$ & 52 & - & - & - & 9 & 20 & NS & $P<0.005$ & - & - \\
\hline & Bjerke et al. [33] & 2011 & $\uparrow$ & 30 & - & - & - & 26 & 30 & $P<0.005$ & NS & - & - \\
\hline \multirow[t]{3}{*}{$\begin{array}{l}\text { Phospho-tau } \\
\left(\tau_{p-181}\right)\end{array}$} & $\begin{array}{l}\text { Paraskevas et al. } \\
\text { [103] }\end{array}$ & 2009 & $\rightarrow$ & 68 & - & 23 & - & - & 92 & NS & $P<0.01$ & - & $\begin{array}{l}\text { Sn } 84 \% \\
\text { Sp79\% }\end{array}$ \\
\hline & Bjerke et al. [72] & 2009 & $\rightarrow$ & 52 & - & - & - & 9 & 20 & NS & $P<0.005$ & - & - \\
\hline & Bjerke et al. [33] & 2011 & $\rightarrow$ & 30 & - & - & - & 26 & 30 & NS & $P<0.05$ & - & - \\
\hline \multirow[t]{3}{*}{$A \beta_{42}$} & $\begin{array}{l}\text { Paraskevas et al. } \\
{[103]}\end{array}$ & 2009 & $\rightarrow$ & 68 & - & 23 & - & -- & 92 & NS & NS & - & $\begin{array}{l}\text { Sn } 73 \% \\
\text { Sp } 70 \%\end{array}$ \\
\hline & Bjerke et al. [72] & 2009 & $\downarrow$ & 52 & - & - & - & 9 & 20 & $P<0.05$ & $P<0.005$ & - & - \\
\hline & Bjerke et al. [33] & 2011 & $\downarrow$ & 30 & - & - & - & 26 & 30 & $P<0.001$ & NS & - & - \\
\hline $\begin{array}{l}A \beta_{42}, \tau_{T}, \tau_{p-181} \\
\text { (combination) }\end{array}$ & $\begin{array}{l}\text { Paraskevas et al. } \\
\text { [103] }\end{array}$ & 2009 & $\uparrow$ & 68 & - & 23 & - & $-^{-}$ & 92 & NS & $P<0.01$ & $-^{-}$ & $\begin{array}{l}\text { Sn } 87 \% \\
\text { Sp } 89 \%\end{array}$ \\
\hline $\mathrm{SAPP}_{\beta}$ & Bjerke et al. [77] & 2014 & & & & & & & & $\begin{array}{l}\text { Correlation with } \\
\text { WML }\end{array}$ & - & - & - \\
\hline
\end{tabular}

VaD Vascular Dementia, VCI Vascular Cognitive Impairment, SSVD Subcortical Small Vessel Disease, AD Alzheimer's disease, HC Healthy Controls, NC Neurological Controls, Sn/Sp Sensitivity/Specificity, $n$ number of controls/patients, $\downarrow$ reduced levels, $\uparrow$ increased levels, $\rightarrow$ no difference vs. controls, - not included, NS Not Significant 
validation and standardization in large multi-centers longitudinal studies.

\section{Conclusion and future directions}

VCI-SSVD is a common neurocognitive disorder with similar clinical manifestations similar to other disorders, such as AD. Underestimation of the impact of SSVD on cognition and insufficient knowledge of SSVD in AD may explain why VCI-SSVD is under-recognized in clinical practice and not often studied in research contexts. Biochemical markers may be of help for the (differential) diagnosis of VCI-SSVD. They can also be used for identifying patients with preclinical SSVD from apparently healthy controls. Furthermore, they have a potential to define a spectrum disorder with pure subcortical vascular disease (i.e. Binswanger's disease) at one end of the spectrum and pure $\mathrm{AD}$ at the other. In between will be the large group of MD patients that will remain a major diagnostic challenge.

This review of all biological markers studied in patients with VCI-SSVD identified several fluid biomarkers with evidence for use in diagnostic settings, while others are too early to be considered as potential SSVD biomarkers. There is little value of blood tests at this time since none of the above biomarkers have been adequately studied, whereas CSF helps to separate vascular and neurodegenerative causes based on the presence of $\mathrm{BCB} / \mathrm{BBB}$ disruption and extracellular matrix breakdown. Obviously, many of the CSF reports cited in this review are based on small series of cases. Replication studies should be done to ensure the reproducibility of the results and calculation of positive and negative predictive values should be provided. At present, it is unlikely that single markers may be sufficient for diagnostic and differentiating purposes. Instead, a combination of biochemical and imaging markers as well as psychometrics will be necessary to improve the diagnostic accuracy.

A third potential use of fluid biomarkers is their application as surrogates for disease progression e.g. in clinical pharmacological trials. For that purpose, such biomarkers could be used if different levels of the biomarkers can reflect patients' clinical severity or extent of WML. If a biomarker fulfills this definition, it could be very valuable in clinical trials obviating the need for repeated expensive MRI examinations.

A fourth potential use of fluid biomarkers is to clarify the pathogenesis of the disorder, for example to verify an inflammatory underlying process, perhaps in a subgroup of patients, thus suggesting a (novel) target for therapy. Clearly, much further work needs to be done along these lines.

The search for an optimal panel of biomarkers with high sensitivity and specificity through a collaborative international network of biobanks, multi-center collections based on large patient cohorts, combined with population genetics, clinical trials and harmonized protocols and procedures will provide the crucial tools needed to enhance the likelihood of success in identifying valid biomarkers in VCI-SSVD [157]. In addition, research will benefit from innovative statistical approaches that allow handling large datasets, e.g. strategies used in the field of artificial intelligence. With combined efforts, the development of biomarkers in the VCI-SSVD field may not only foster therapeutic progress in VCI-SSVD but also in AD.

\begin{abstract}
Abbreviations
AD: Alzheimer's disease; ADMA: Asymmetric dimethylarginine; A 440 : Betaamyloid peptide with 40 amino acids; $A \beta 42$ : Beta-amyloid peptide with 42 amino acids; BBB: Blood-brain barrier; BCB: Blood-cerebrospinal fluid barrier; BNP: B-type natriuretic peptide; CRP: C reactive protein; CSF: Cerebrospinal fluid; CT: Computed tomography; CXCL-9: Chemokine (C-X-C motif) ligand 9; FTD: Fronto-temporal dementia; GFAP: Glial fibrillary acidic protein; Hcy: Homocysteine; IL-6: Interleukin-6; ILs: Interleukins; MAG: Myelinassociated glycoprotein; MBP: Myelin basic protein; MD: Mixed type dementia; MIG: Monokine induced by $\gamma$-interferon; MMPs: Matrix metalloproteinases; MRI: Magnetic resonance imaging; NF-H: Neurofilament heavy subunit; NF-L: Neurolfilament light subunit; NF-M: Neurofilament medium subunit; NFs: Neurofilaments; NIHSS: National institute of health stroke scale; NSE: Neuron specific enolase; P-tau: Hyperphosphorylated tau; QA: Cerebrospinal fluid/serum albumin quotient; SAPPB: soluble amyloid precursor protein $\beta$ peptide; sE-selectin: soluble E-selectin; sICAM-1: soluble intercellular adhesion molecule-1; SSVD: Subcortical small vessel disease; sVCAM-1: soluble vascular cell adhesion molecule-1; TIMP-1: Tissue inhibitor of metalloproteinases-1; T-tau: Total tau; VCl: Vascular cognitive impairment; VCI-SSVD: Vascular cognitive impairment of the subcortical small vessel disease type; WML: White matter lesions
\end{abstract}

\section{Acknowledgements}

We would like to thank Dr. Vasilios Constandinides for his contribution in the preparation of the final version of the manuscript.

\section{Funding}

No funding was obtained for the preparation of the present manuscript.

\section{Availability of data and materials}

Data sharing is not applicable to this article as no datasets were generated during the current study.

\section{Author's contributions}

AW and EK contributed substantially and equally to the conception and design of the consensus report. Drafting and revising the manuscript critically for intellectual content was jointly performed by AW, EK, MB, SE, DH, $B H, M J, M K, L L, B M, S M, A M, E M-L, G P, B P, R R, L T, G T, G W, A K, M B$ and GR. All authors approved the final version of the manuscript.

\section{Competing interests}

EBM-L - none, EK - none, GP - none, MGK - none, ADK - none, MB - none. AW was consultant/speaker for Esai, Nutricia and received research funding from Roche diagnostics. SE was/is consultant for and/or received research funding from Janssen, ADxNeuroSciences, Innogenetics/Fujirebio Europe, Lundbeck, Pfizer, Novartis, UCB, Roche diagnostics, Nutricia/Danone.

Consent for publication

Not applicable.

Ethics approval and consent to participate

The article is based on original publications from ethically approved studies. 


\section{Publisher's Note}

Springer Nature remains neutral with regard to jurisdictional claims in published maps and institutional affiliations.

\section{Author details}

'Department of Psychiatry and Neurochemistry, Institute of Neuroscience and Physiology, Sahlgrenska Academy at the University of Gothenburg, Mölndal, Sweden. ${ }^{2} 1$ st Department of Neurology, Eginition Hospital, Medical School, National and Kapodistrian University of Athens, Athens, Greece. ${ }^{3}$ Department of Neurology, University Hospital Centre Zagreb, Medical School, University of Zagreb, Zagreb, Croatia. ${ }^{4}$ Memory Clinic and Department of Neurology, Hospital Network Antwerp (ZNA) Middelheim and HogeBeuken, Antwerp, Belgium. ${ }^{5}$ Reference Center for Biological Markers of Dementia, Department of Biomedical Sciences, Institute Born-Bunge, University of Antwerp, Antwerp, Belgium. ${ }^{6}$ Department of Neurology, University Hospital Essen, Essen, Germany. 'Department of Neurology, University of California, Irvine, California, USA. ${ }^{8}$ Department of Neurology, University Medical Center Ljubljana, Ljubljana, Slovenia. ${ }^{9}$ Department of Veterinary Sciences, University of Turin, Turin, Italy. ${ }^{10}$ Department of Neurology, University Hospital "Alexandrovska", Medical University, Sofia, Bulgaria. ${ }^{11}$ Institute of Neuroscience, Campus for Ageing and Vitality, Newcastle University, Newcastle upon Tyne NE4 5PL, UK. ${ }^{12}$ Department of Neurology, Colentina Clinical Hospital, School of Medicine, 'Carol Davila' University of Medicine and Pharmacy, Bucharest, Romania. ${ }^{13}$ Brain Bank Consultants, Amsterdam, The Netherlands. ${ }^{14}$ 2nd Department of Neurology, Attikon Hospital, Medical School, National and Kapodistrian University of Athens, Athens, Greece. ${ }^{15}$ School of Public Health, University of Haifa, Haifa, Israel. ${ }^{16}$ Department of Neurology, Sackler School of Medicine, Tel Aviv University, Tel Aviv, Israel. ${ }^{17}$ University of New Mexico Health Sciences Center, Albuquerque, NM 87131, USA. ${ }^{18}$ Memory Clinic at Department of Neuropsychiatry, Sahlgrenska University Hospital, Institute of Neuroscience and Physiology at Sahlgrenska Academy, University of Gothenburg, Wallinsgatan 6, SE-431 41 Mölndal, Sweden.

Received: 20 September 2016 Accepted: 9 May 2017 Published online: 23 May 2017

\section{References}

1. Erkinjuntti T. Diagnosis and management of vascular cognitive impairment and dementia. J Neural Transm Suppl. 2002;63:91-109.

2. Roman GC, Erkinjuntti T, Wallin A, Pantoni L, Chui HC. Subcortical ischaemic vascular dementia. Lancet Neurol. 2002;1(7):426-36.

3. Salvadori E, Poggesi A, Valenti R, Della Rocca E, Diciotti S, Mascalchi M, et al. The rehabilitation of attention in patients with mild cognitive impairment and brain subcortical vascular changes using the attention process trainingII. The RehAtt study: rationale, design and methodology. Neurol Sci. 2016; 37(10):1653-62.

4. Jia J, Wei C, Liang J, Zhou A, Zuo X, Song H, et al. The effects of DL-3-nbutylphthalide in patients with vascular cognitive impairment without dementia caused by subcortical ischemic small vessel disease: a multicentre, randomized, double-blind, placebo-controlled trial. Alzheimers Dement. 2016;12(2):89-99.

5. Kalaria RN. Neuropathological diagnosis of vascular cognitive impairment and vascular dementia with implications for Alzheimer's disease. Acta Neuropathol. 2016;131(5):659-85.

6. de Leeuw FE, de Groot JC, Oudkerk M, Witteman JC, Hofman A, van Gijn J, et al. Hypertension and cerebral white matter lesions in a prospective cohort study. Brain. 2002;125(Pt 4):765-72

7. Abraham HM, Wolfson L, Moscufo N, Guttmann CR, Kaplan RF, White WB. Cardiovascular risk factors and small vessel disease of the brain: blood pressure, white matter lesions, and functional decline in older persons. J Cereb Blood Flow Metab. 2016;36(1):132-42.

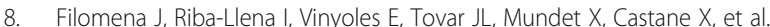
Short-term blood pressure variability relates to the presence of subclinical brain small vessel disease in primary hypertension. Hypertension. 2015;66(3): 634-40. discussion 445

9. Pavlovic AM, Pekmezovic T, Zidverc Trajkovic J, Svabic Medjedovic T, Veselinovic N, Radojicic A, et al. Baseline characteristic of patients presenting with lacunar stroke and cerebral small vessel disease may predict future development of depression. Int J Geriatr Psychiatry. 2016;31(1):58-65.
10. Toyoda G, Bokura H, Mitaki S, Onoda K, Oguro H, Nagai A, et al. Association of mild kidney dysfunction with silent brain lesions in neurologically normal subjects. Cerebrovasc Dis Extra. 2015;5(1):22-7.

11. Toyoda K. Cerebral small vessel disease and chronic kidney disease. J Stroke. 2015:17(1):31-7.

12. Staals J, Makin SD, Doubal FN, Dennis MS, Wardlaw JM. Stroke subtype, vascular risk factors, and total MRI brain small-vessel disease burden. Neurology. 2014;83(14):1228-34.

13. Ott A, Stolk RP, van Harskamp F, Pols HA, Hofman A, Breteler MM. Diabetes mellitus and the risk of dementia: the Rotterdam study. Neurology. 1999; 53(9):1937-42.

14. Dearborn JL, Schneider AL, Sharrett AR, Mosley TH, Bezerra DC, Knopman DS, et al. Obesity, insulin resistance, and incident small vessel disease on magnetic resonance imaging: atherosclerosis risk in communities study. Stroke. 2015:46(11):3131-6.

15. Alagiakrishnan K, Hsueh J, Zhang E, Khan K, Senthilselvan A. Small vessel disease/white matter disease of the brain and its association with osteoporosis. J Clin Med Res. 2015;7(5):297-302.

16. Lahousse L, Tiemeier H, Ikram MA, Brusselle GG. Chronic obstructive pulmonary disease and cerebrovascular disease: a comprehensive review. Respir Med. 2015:109(11):1371-80.

17. Durgan DJ, Bryan RM Jr. Cerebrovascular consequences of obstructive sleep apnea. J Am Heart Assoc. 2012;1(4):e000091.

18. Makedonov I, Black SE, Maclntosh BJ. Cerebral small vessel disease in aging and Alzheimer's disease: a comparative study using MRI and SPECT. Eur J Neurol. 2013;20(2):243-50

19. Ortner M, Kurz A, Alexopoulos P, Auer F, Diehl-Schmid J, Drzezga A, et al. Small vessel disease, but neither amyloid load nor metabolic deficit, is dependent on age at onset in Alzheimer's disease. Biol Psychiatry. 2015;77(8):704-10.

20. Kim HJ, Im K, Kwon H, Lee JM, Kim C, Kim YJ, et al. Clinical effect of white matter network disruption related to amyloid and small vessel disease. Neurology. 2015:85(1):63-70.

21. Jang YK, Kwon H, Kim YJ, Jung NY, Lee JS, Lee J, et al. Early- vs late-onset subcortical vascular cognitive impairment. Neurology. 2016;86(6):527-34

22. Bersano A, Debette S, Zanier ER, Lanfranconi S, De Simoni MG, Zuffardi O, et al. The genetics of small-vessel disease. Curr Med Chem. 2012;19(24):4124-41.

23. Popescu BO, Toescu EC, Popescu LM, Bajenaru O, Muresanu DF, Schultzberg $M$, et al. Blood-brain barrier alterations in ageing and dementia. J Neurol Sci. 2009;283(1-2):99-106.

24. Ueno M, Chiba Y, Matsumoto K, Murakami R, Fujihara R, Kawauchi M, et al. Blood-brain barrier damage in vascular dementia. Neuropathology. 2016; 36(2):115-24.

25. Srinivasan V, Braidy N, Chan EK, Xu YH, Chan DK. Genetic and environmental factors in vascular dementia: an update of blood brain barrier dysfunction. Clin Exp Pharmacol Physiol. 2016;43(5):515-21.

26. Wang M, Norman JE, Srinivasan VJ, Rutledge JC. Metabolic, inflammatory, and microvascular determinants of white matter disease and cognitive decline. Am J Neurodegener Dis. 2016;5(5):171-77.

27. Tibbling $\mathrm{G}$, Link $H$, Ohman S. Principles of albumin and IgG analyses in neurological disorders. I. Establishment of reference values. Scand J Clin Lab Invest. 1977:37(5):385-90.

28. Blennow K, Hampel H, Weiner M, Zetterberg H. Cerebrospinal fluid and plasma biomarkers in Alzheimer disease. Nat Rev Neurol. 2010;6(3):131-44.

29. Farrall AJ, Wardlaw JM. Blood-brain barrier: ageing and microvascular diseasesystematic review and meta-analysis. Neurobiol Aging. 2009;30(3):337-52.

30. Wallin A, Blennow K, Fredman P, Gottfries CG, Karlsson I, Svennerholm L. Blood brain barrier function in vascular dementia. Acta Neurol Scand. 1990; 81(4):318-22.

31. Wallin A, Sjogren M, Edman A, Blennow K, Regland B. Symptoms, vascular risk factors and blood-brain barrier function in relation to $C T$ white-matter changes in dementia. Eur Neurol. 2000;44(4):229-35.

32. Wallin A, Sjogren M. Cerebrospinal fluid cytoskeleton proteins in patients with subcortical white-matter dementia. Mech Ageing Dev. 2001;122(16):1937-49.

33. Bjerke $\mathrm{M}$, Zetterberg $\mathrm{H}$, Edman $\mathrm{A}$, Blennow $\mathrm{K}$, Wallin $\mathrm{A}$, Andreasson U. Cerebrospinal fluid matrix metalloproteinases and tissue inhibitor of metalloproteinases in combination with subcortical and cortical biomarkers in vascular dementia and Alzheimer's disease. J Alzheimers Dis. 2011;27(3): 665-76.

34. Rosenberg GA, Bjerke M, Wallin A. Multimodal markers of inflammation in the subcortical ischemic vascular disease type of vascular cognitive impairment. Stroke. 2014;45(5):1531-8. 
35. Marchi N, Cavaglia M, Fazio V, Bhudia S, Hallene K, Janigro D. Peripheral markers of blood-brain barrier damage. Clin Chim Acta. 2004;342(1-2): $1-12$

36. Levada OA, Trailin AV. [Serum level of S100B as a marker of progression of vascular mild cognitive impairment into subcortical vascular dementia and therapy effectiveness]. Likars'ka sprava/Ministerstvo okhorony zdorov'ia Ukrainy. 2012;2(3-4):53-59.

37. Gao Q, Fan Y, Mu LY, Ma L, Song ZQ, Zhang YN. S100B and ADMA in cerebral small vessel disease and cognitive dysfunction. J Neurol Sci. 2015; 354(1-2):27-32.

38. Rothermundt M, Arolt V, Wiesmann M, Missler U, Peters M, Rudolf S, et al. S$100 \mathrm{~B}$ is increased in melancholic but not in non-melancholic major depression. J Affect Disord. 2001;66(1):89-93.

39. Dittrich $S$, Sunyakumthorn $P$, Rattanavong S, Phetsouvanh R, Panyanivong $P$, Sengduangphachanh $\mathrm{A}$, et al. Blood-brain barrier function and biomarkers of central nervous system injury in Rickettsial versus other neurological infections in Laos. AmJTrop Med Hyg. 2015;93(2):232-7.

40. Mecocci P, Parnetti L, Romano G, Scarelli A, Chionne F, Cecchetti R, et al. Serum anti-GFAP and anti-S100 autoantibodies in brain aging, Alzheimer's disease and vascular dementia. J Neuroimmunol. 1995;57(1-2):165-70.

41. Blennow K, Wallin A, Ekman R. Neuron specific enolase in cerebrospinal fluid: a biochemical marker for neuronal degeneration in dementia disorders? J Neural Transm Park Dis Dement Sect. 1994;8(3):183-91.

42. Wallin A, Blennow K, Rosengren LE. Glial fibrillary acidic protein in the cerebrospinal fluid of patients with dementia. Dementia. 1996;7(5):267-72.

43. Heneka MT, Golenbock DT, Latz E. Innate immunity in Alzheimer's disease. Nat Immunol. 2015;16(3):229-36.

44. Holmes C. Review: systemic inflammation and Alzheimer's disease. Neuropathol Appl Neurobiol. 2013;39(1):51-68.

45. Aribisala BS, Wiseman S, Morris Z, Valdes-Hernandez MC, Royle NA, Maniega SM, et al. Circulating inflammatory markers are associated with magnetic resonance imaging-visible perivascular spaces but not directly with white matter hyperintensities. Stroke. 2014;45(2):605-7.

46. Satizabal CL, Zhu YC, Mazoyer B, Dufouil C, Tzourio C. Circulating IL-6 and CRP are associated with MRI findings in the elderly: the 3C-Dijon study. Neurology. 2012;78(10):720-7.

47. Shoamanesh A, Preis SR, Beiser AS, Vasan RS, Benjamin EJ, Kase CS, et al. Inflammatory biomarkers, cerebral microbleeds, and small vessel disease: Framingham heart study. Neurology. 2015;84(8):825-32.

48. van Dijk EJ, Prins ND, Vermeer SE, Vrooman HA, Hofman A, Koudstaal PJ, et al. C-reactive protein and cerebral small-vessel disease: the Rotterdam scan study. Circulation. 2005;112(6):900-5.

49. Engelhart MJ, Geerlings MI, Meijer J, Kiliaan A, Ruitenberg A, van Swieten JC, et al. Inflammatory proteins in plasma and the risk of dementia: the rotterdam study. Arch Neurol. 2004;61(5):668-72.

50. Ravaglia G, Forti P, Maioli F, Chiappelli M, Montesi F, Tumini E, et al. Blood inflammatory markers and risk of dementia: the Conselice study of brain aging. Neurobiol Aging. 2007;28(12):1810-20.

51. Miralbell J, Soriano JJ, Spulber G, Lopez-Cancio E, Arenillas JF, Bargallo N, et al. Structural brain changes and cognition in relation to markers of vascular dysfunction. Neurobiol Aging. 2012;33(5):1003.e1009-17.

52. Wersching H, Duning T, Lohmann H, Mohammadi S, Stehling C, Fobker M, et al. Serum C-reactive protein is linked to cerebral microstructural integrity and cognitive function. Neurology. 2010;74(13):1022-9.

53. Bettcher BM, Yaffe K, Boudreau RM, Neuhaus J, Aizenstein H, Ding J, et al. Declines in inflammation predict greater white matter microstructure in older adults. Neurobiol Aging. 2015;36(2):948-54.

54. Vilar-Bergua A, Riba-Llena I, Nafria C, Bustamante A, Llombart V, Delgado P, et al. Blood and CSF biomarkers in brain subcortical ischemic vascular disease: involved pathways and clinical applicability. J Cereb Blood Flow Metab. 2016;36(1):55-71.

55. Tarkowski E, Blennow K, Wallin A, Tarkowski A. Intracerebral production of tumor necrosis factor-alpha, a local neuroprotective agent, in Alzheimer disease and vascular dementia. J Clin Immunol. 1999:19(4):223-30.

56. Tarkowski E, Issa R, Sjogren M, Wallin A, Blennow K, Tarkowski A, et al. Increased intrathecal levels of the angiogenic factors VEGF and TGF-beta in Alzheimer's disease and vascular dementia. Neurobiol Aging. 2002;23(2): 237-43.

57. Ohrfelt A, Andreasson U, Simon A, Zetterberg H, Edman A, Potter W, et al. Screening for new biomarkers for subcortical vascular dementia and Alzheimer's disease. Dement Geriatr Cogn Dis Extra. 2011;1(1):31-42.
58. Ozturk C, Ozge A, Yalin OO, Yilmaz IA, Delialioglu N, Yildiz C. Tet al. The diagnostic role of serum inflammatory and soluble proteins on dementia subtypes: correlation with cognitive and functional decline. Behav Neurol. 2007;18(4):207-15.

59. Olsson B, Hertze J, Lautner R, Zetterberg H, Nagga K, Hoglund K, et al. Microglial markers are elevated in the prodromal phase of Alzheimer's disease and vascular dementia. J Alzheimers Dis. 2013;33(1):45-53.

60. Weekman EM, Wilcock DM. Matrix metalloproteinase in blood-brain barrier breakdown in dementia. J Alzheimers Dis. 2016;49(4):893-903.

61. Rosenberg GA. Matrix metalloproteinase-mediated Neuroinflammation in vascular cognitive impairment of the Binswanger type. Cell Mol Neurobiol. 2016;36(2):195-202.

62. Adair JC, Charlie J, Dencoff JE, Kaye JA, Quinn JF, Camicioli RM, et al. Measurement of gelatinase B (MMP-9) in the cerebrospinal fluid of patients with vascular dementia and Alzheimer disease. Stroke. 2004; 35(6):e159-62.

63. Candelario-Jalil E, Thompson J, Taheri S, Grossetete M, Adair JC, Edmonds E, et al. Matrix metalloproteinases are associated with increased blood-brain barrier opening in vascular cognitive impairment. Stroke. 2011;42(5):1345-50.

64. Hoffman PN, Cleveland DW, Griffin JW, Landes PW, Cowan NJ, Price DL. Neurofilament gene expression: a major determinant of axonal caliber. Proc Natl Acad Sci U S A. 1987;84(10):3472-6.

65. Perrot $R$, Berges $R$, Bocquet $A$, Eyer J. Review of the multiple aspects of neurofilament functions, and their possible contribution to neurodegeneration. Mol Neurobiol. 2008;38(1):27-65.

66. Rosengren LE, Karlsson JE, Karlsson JO, Persson LI, Wikkelso C. Patients with amyotrophic lateral sclerosis and other neurodegenerative diseases have increased levels of neurofilament protein in CSF. J Neurochem. 1996;67(5): 2013-8.

67. Hu YY, He SS, Wang XC, Duan QH, Khatoon S, Iqbal K, et al. Elevated levels of phosphorylated neurofilament proteins in cerebrospinal fluid of Alzheimer disease patients. Neurosci Lett. 2002;320(3):156-60.

68. Norgren N, Karlsson JE, Rosengren L, Stigbrand T. Monoclonal antibodies selective for low molecular weight neurofilaments. Hybrid Hybridomics. 2002;21(1):53-9.

69. Gresle MM, Butzkueven H, Shaw G. Neurofilament proteins as body fluid biomarkers of neurodegeneration in multiple sclerosis. Mult Scler Int. 2011; 2011:315406.

70. Friede RL, Samorajski T. Axon caliber related to neurofilaments and microtubules in sciatic nerve fibers of rats and mice. Anat Rec. 1970;167(4): 379-87.

71. Sjogren M, Blomberg M, Jonsson M, Wahlund LO, Edman A, Lind K, et al. Neurofilament protein in cerebrospinal fluid: a marker of white matter changes. J Neurosci Res. 2001;66(3):510-6.

72. Bjerke M, Andreasson U, Rolstad S, Nordlund A, Lind K, Zetterberg $\mathrm{H}$, et al. Subcortical vascular dementia biomarker pattern in mild cognitive impairment. Dement Geriatr Cogn Disord. 2009;28(4):348-56.

73. Jonsson M, Zetterberg $H$, van Straaten $E$, Lind $K$, Syversen S, Edman A, et al. Cerebrospinal fluid biomarkers of white matter lesions - cross-sectional results from the LADIS study. Eur J Neurol. 2010;17(3):377-82.

74. Norgren N, Rosengren L, Stigbrand T. Elevated neurofilament levels in neurological diseases. Brain Res. 2003;987(1):25-31.

75. Skillback T, Farahmand B, Bartlett JW, Rosen C, Mattsson N, Nagga K, et al. CSF neurofilament light differs in neurodegenerative diseases and predicts severity and survival. Neurology. 2014;83(21):1945-53.

76. Petzold A, Keir G, Warren J, Fox N, Rossor MN. A systematic review and meta-analysis of CSF neurofilament protein levels as biomarkers in dementia. Neurodegener Dis. 2007;4(2-3):185-94.

77. Bjerke M, Jonsson M, Nordlund A, Eckerstrom C, Blennow K, Zetterberg H, et al. Cerebrovascular biomarker profile is related to white matter disease and ventricular dilation in a LADIS Substudy. Dement Geriatr Cogn Dis Extra. 2014;4(3):385-94.

78. Brettschneider J, Petzold A, Schottle D, Claus A, Riepe M, Tumani H. The neurofilament heavy chain $(\mathrm{NfH})$ in the cerebrospinal fluid diagnosis of Alzheimer's disease. Dement Geriatr Cogn Disord. 2006;21(5-6):291-5.

79. Omlin FX, Webster HD, Palkovits CG, Cohen SR. Immunocytochemical localization of basic protein in major dense line regions of central and peripheral myelin. J Cell Biol. 1982;95(1):242-8.

80. Yin X, Crawford TO, Griffin JW, Tu P, Lee VM, Li C, et al. Myelin-associated glycoprotein is a myelin signal that modulates the caliber of myelinated axons. J Neurosci. 1998;18(6):1953-62. 
81. Wallin A, Blennow K, Uhlemann C, Langstrom G, Gottfries CG. White matter low attenuation on computed tomography in Alzheimer's disease and vascular dementia-diagnostic and pathogenetic aspects. Acta Neurol Scand. 1989;80(6):518-23.

82. Kalaria RN, Erkinjuntti T. Small vessel disease and subcortical vascular dementia. J Clin Neurol. 2006;2(1):1-11.

83. Brouns $R$, De Vil B, Cras P, De Surgeloose D, Marien P, De Deyn PP. Neurobiochemical markers of brain damage in cerebrospinal fluid of acute ischemic stroke patients. Clin Chem. 2010;56(3):451-8.

84. Hjalmarsson C, Bjerke M, Andersson B, Blennow K, Zetterberg H, Aberg ND, et al. Neuronal and glia-related biomarkers in cerebrospinal fluid of patients with acute ischemic stroke. J Cent Nerv Syst Dis. 2014;6:51-8.

85. Fredman P, Wallin A, Blennow K, Davidsson P, Gottfries CG, Svennerholm L. Sulfatide as a biochemical marker in cerebrospinal fluid of patients with vascular dementia. Acta Neurol Scand. 1992;85(2):103-6.

86. Tullberg M, Mansson JE, Fredman P, Lekman A, Blennow K, Ekman R, et al. CSF sulfatide distinguishes between normal pressure hydrocephalus and subcortical arteriosclerotic encephalopathy. J Neurol Neurosurg Psychiatry. 2000;69(1):74-81.

87. Jonsson M, Zetterberg H, Rolstad S, Edman A, Gouw AA, Bjerke M, et al. Low cerebrospinal fluid sulfatide predicts progression of white matter lesions: the LADIS study. Dement Geriatr Cogn Disord. 2012;34(1):61-7.

88. Han X, Fagan AM, Cheng H, Morris JC, Xiong C, Holtzman DM. Cerebrospinal fluid sulfatide is decreased in subjects with incipient dementia. Ann Neurol. 2003;54(1):115-9.

89. Tarkowski E, Tullberg M, Fredman P, Wikkelso C. Correlation between intrathecal sulfatide and TNF-alpha levels in patients with vascular dementia. Dement Geriatr Cogn Disord. 2003;15(4):207-11.

90. Zetterberg H, Lautner R, Skillback T, Rosen C, Shahim P, Mattsson N, et al. CSF in Alzheimer's disease. Adv Clin Chem. 2014;65:143-72.

91. Cavedo E, Lista S, Khachaturian Z, Aisen P, Amouyel P, Herholz K, et al. The road ahead to cure Alzheimer's disease: development of biological markers and Neuroimaging methods for prevention trials across all stages and target populations. J Prev Alzheimers Dis. 2014;1(3):181-202.

92. McKhann GM, Knopman DS, Chertkow H, Hyman BT, Jack CR Jr, Kawas CH, et al. The diagnosis of dementia due to Alzheimer's disease: recommendations from the National Institute on Aging-Alzheimer's Association workgroups on diagnostic guidelines for Alzheimer's disease. Alzheimers Dement. 2011;7(3):263-9.

93. Dubois B, Feldman HH, Jacova C, Hampel H, Molinuevo JL, Blennow K, et al. Advancing research diagnostic criteria for Alzheimer's disease: the IWG-2 criteria. Lancet Neurol. 2014;13(6):614-29.

94. Mori H, Hosoda K, Matsubara E, Nakamoto T, Furiya Y, Endoh R, et al. Tau in cerebrospinal fluids: establishment of the sandwich ELISA with antibody specific to the repeat sequence in tau. Neurosci Lett. 1995;186(2-3):181-3.

95. Kapaki E, Paraskevas GP, Zalonis I, Zournas C. CSF tau protein and betaamyloid (1-42) in Alzheimer's disease diagnosis: discrimination from normal ageing and other dementias in the Greek population. Eur J Neurol. 2003; 10(2):119-28.

96. Paraskevas GP, Kapaki E, Liappas I, Theotoka I, Mamali I, Zournas C, et al. The diagnostic value of cerebrospinal fluid tau protein in dementing and nondementing neuropsychiatric disorders. J Geriatr Psychiatry Neurol. 2005;18(3):163-73.

97. Tato RE, Frank A, Hernanz A. Tau protein concentrations in cerebrospinal fluid of patients with dementia of the Alzheimer type. J Neurol Neurosurg Psychiatry. 1995;59(3):280-3.

98. Andreasen N, Minthon L, Davidsson P, Vanmechelen E, Vanderstichele H, Winblad B, et al. Evaluation of CSF-tau and CSF-Abeta42 as diagnostic markers for Alzheimer disease in clinical practice. Arch Neurol. 2001;58(3):373-9.

99. Andreasen N, Vanmechelen E, Van de Voorde A, Davidsson P, Hesse C, Tarvonen S, et al. Cerebrospinal fluid tau protein as a biochemical marker for Alzheimer's disease: a community based follow up study. J Neurol Neurosurg Psychiatry. 1998;64(3):298-305.

100. Jia JP, Meng R, Sun YX, Sun WJ, Ji XM, Jia LF. Cerebrospinal fluid tau, Abeta1-42 and inflammatory cytokines in patients with Alzheimer's disease and vascular dementia. Neurosci Lett. 2005;383(1-2):12-6.

101. Stefani A, Bernardini S, Panella M, Pierantozzi M, Nuccetelli M, Koch G, et al. AD with subcortical white matter lesions and vascular dementia: CSF markers for differential diagnosis. J Neurol Sci. 2005;237(1-2):83-8.

102. Leszek J, Malyszczak K, Janicka B, Kiejna A, Wiak A. Total tau in cerebrospinal fluid differentiates Alzheimer's disease from vascular dementia. Med Sci Monit. 2003;9(11):CR484-8.
103. Paraskevas GP, Kapaki E, Papageorgiou SG, Kalfakis N, Andreadou E, Zalonis I, et al. CSF biomarker profile and diagnostic value in vascular dementia. Eur J Neurol. 2009;16(2):205-11.

104. Vandermeeren $M$, Mercken $M$, Vanmechelen $E$, Six J, van de Voorde $A$, Martin JJ, et al. Detection of tau proteins in normal and Alzheimer's disease cerebrospinal fluid with a sensitive sandwich enzyme-linked immunosorbent assay. J Neurochem. 1993;61(5):1828-34.

105. Vigo-Pelfrey C, Seubert P, Barbour R, Blomquist C, Lee M, Lee D, et al. Elevation of microtubule-associated protein tau in the cerebrospinal fluid of patients with Alzheimer's disease. Neurology. 1995;45(4):788-93.

106. Kaerst L, Kuhlmann A, Wedekind D, Stoeck K, Lange P, Zerr I. Cerebrospinal fluid biomarkers in Alzheimer's disease, vascular dementia and ischemic stroke patients: a critical analysis. J Neurol. 2013;260(11):2722-7.

107. Hermann P, Romero C, Schmidt C, Reis C, Zerr I. CSF biomarkers and neuropsychological profiles in patients with cerebral small-vessel disease. PLoS One. 2014;9(8):e105000.

108. Wallin A, Nordlund A, Jonsson M, Blennow K, Zetterberg H, Ohrfelt A, et al. Alzheimer's disease-subcortical vascular disease spectrum in a hospitalbased setting: overview of results from the Gothenburg $\mathrm{MCl}$ and dementia studies. J Cereb Blood Flow Metab. 2016;36(1):95-113.

109. Rosenberg GA, Prestopnik J, Adair JC, Huisa BN, Knoefel J, Caprihan A, et al. Validation of biomarkers in subcortical ischaemic vascular disease of the Binswanger type: approach to targeted treatment trials. J Neurol Neurosurg Psychiatry. 2015;86(12):1324-30.

110. Lewczuk P, Esselmann H, Otto M, Maler JM, Henkel AW, Henkel MK, et al. Neurochemical diagnosis of Alzheimer's dementia by CSF Abeta42, Abeta42/Abeta40 ratio and total tau. Neurobiol Aging. 2004;25(3):273-81.

111. Chasseigneaux S, Allinquant B. Functions of Abeta, sAPPalpha and sAPPbeta : similarities and differences. J Neurochem. 2012;120(Suppl 1):99-108.

112. Rosen C, Andreasson U, Mattsson N, Marcusson J, Minthon L, Andreasen N, et al. Cerebrospinal fluid profiles of amyloid beta-related biomarkers in Alzheimer's disease. NeuroMolecular Med. 2012;14(1):65-73.

113. Kohriyama T, Yamaguchi S, Tanaka E, Yamamura Y, Nakamura S. Coagulation and fibrinolytic parameters as predictors for small-vessel disease revealed by magnetic resonance imaging of the brain. Rinsho Shinkeigaku. 1996;36(5):640-7.

114. Wiseman S, Marlborough F, Doubal F, Webb DJ, Wardlaw J. Blood markers of coagulation, fibrinolysis, endothelial dysfunction and inflammation in lacunar stroke versus non-lacunar stroke and non-stroke: systematic review and meta-analysis. Cerebrovasc Dis. 2014;37(1):64-75.

115. Ritz MF, Grond-Ginsbach C, Kloss M, Tolnay M, Fluri F, Bonati LH, et al. Identification of inflammatory, metabolic, and cell survival pathways contributing to cerebral small vessel disease by postmortem gene expression microarray. Curr Neurovasc Res. 2016;13(1):58-67.

116. Kilpatrick TJ, Matkovic Z, Davis SM, McGrath CM, Dauer RJ. Hematologic abnormalities occur in both cortical and lacunar infarction. Stroke. 1993; 24(12):1945-50.

117. Bath PM, Blann A, Smith N, Butterworth RJ. Von Willebrand factor, P-selectin and fibrinogen levels in patients with acute ischaemic and haemorrhagic stroke, and their relationship with stroke sub-type and functional outcome. Platelets. 1998:9(3-4):155-9.

118. Salobir B, Sabovic M, Peternel P, Stegnar M, Grad A. Classic risk factors, hypercoagulability and migraine in young women with cerebral lacunar infarctions. Acta Neurol Scand. 2002;105(3):189-95.

119. Jood K, Danielson J, Ladenvall C, Blomstrand C, Jern C. Fibrinogen gene variation and ischemic stroke. J Thromb Haemost. 2008;6(6):897-904.

120. Alvarez-Perez FJ, Castelo-Branco M, Alvarez-Sabin J. Usefulness of measurement of fibrinogen, D-dimer, D-dimer/fibrinogen ratio, $\mathrm{C}$ reactive protein and erythrocyte sedimentation rate to assess the pathophysiology and mechanism of ischaemic stroke. J Neurol Neurosurg Psychiatry. 2011;82(9):986-92.

121. Beer C, Blacker D, Hankey GJ, Puddey IB. Association of clinical and aetiologic subtype of acute ischaemic stroke with inflammation, oxidative stress and vascular function: a cross-sectional observational study. Med Sci Monit. 2011;17(9):CR467-73.

122. Zhang B, Zhang W, Li X, Pu S, Yin J, Yang N, et al. Admission markers predict lacunar and non-lacunar stroke in young patients. Thromb Res. 2011;128(1):14-7.

123. Vischer UM. Von Willebrand factor, endothelial dysfunction, and cardiovascular disease. J Thromb Haemost. 2006:4(6):1186-93.

124. Isenegger J, Meier N, Lammle B, Alberio L, Fischer U, Nedeltchev K, et al. Ddimers predict stroke subtype when assessed early. Cerebrovasc Dis. 2010; 29(1):82-6. 
125. Kario K, Matsuo T, Kobayashi H, Hoshide S, Shimada K. Hyperinsulinemia and hemostatic abnormalities are associated with silent lacunar cerebral infarcts in elderly hypertensive subjects. J Am Coll Cardiol. 2001;37(3):871-7.

126. Kearney-Schwartz A, Rossignol P, Bracard S, Felblinger J, Fay R, Boivin JM, et al. Vascular structure and function is correlated to cognitive performance and white matter hyperintensities in older hypertensive patients with subjective memory complaints. Stroke. 2009;40(4):1229-36.

127. Nagai M, Hoshide S, Kario K. Association of prothrombotic status with markers of cerebral small vessel disease in elderly hypertensive patients. Am J Hypertens. 2012;25(10):1088-94.

128. Colombatti R, De Bon E, Bertomoro A, Casonato A, Pontara E, Omenetto E, et al. Coagulation activation in children with sickle cell disease is associated with cerebral small vessel vasculopathy. PLoS One. 2013;8(10):e78801.

129. Salmaggi A, Gelati M, Dufour A, Corsini E, Pagano S, Baccalini R, et al. Expression and modulation of IFN-gamma-inducible chemokines (IP-10, Mig, and I-TAC) in human brain endothelium and astrocytes: possible relevance for the immune invasion of the central nervous system and the pathogenesis of multiple sclerosis. J Interf Cytokine Res. 2002;22(6):631-40.

130. de Leeuw FE, de Kleine M, Frijns CJ, Fijnheer R, van Gijn J, Kappelle LJ. Endothelial cell activation is associated with cerebral white matter lesions in patients with cerebrovascular disease. Ann N Y Acad Sci. 2002;977:306-14.

131. Deanfield JE, Halcox JP, Rabelink TJ. Endothelial function and dysfunction: testing and clinical relevance. Circulation. 2007;115(10):1285-95.

132. Han JH, Wong KS, Wang YY, Fu JH, Ding D, Hong Z. Plasma level of sICAM-1 is associated with the extent of white matter lesion among asymptomatic elderly subjects. Clin Neurol Neurosurg. 2009;111(10):847-51.

133. Rouhl RP, Damoiseaux JG, Lodder J, Theunissen RO, Knottnerus IL, Staals J, et al. Vascular inflammation in cerebral small vessel disease. Neurobiol Aging. 2012;33(8):1800-6.

134. Craggs L, Hagel C, Kuhlenbaeumer G, Borjesson-Hanson A, Andersen O, Viitanen $M$, et al. Quantitative vascular pathology and phenotyping familial and sporadic cerebral small vessel diseases. Brain Pathol. 2013;23(5):547-57.

135. Lammie GA. Hypertensive cerebral small vessel disease and stroke. Brain Pathol. 2002;12(3):358-70.

136. Giwa MO, Williams J, Elderfield K, Jiwa NS, Bridges LR, Kalaria RN, et al. Neuropathologic evidence of endothelial changes in cerebral small vessel disease. Neurology. 2012;78(3):167-74.

137. Hainsworth AH, Oommen AT, Bridges LR. Endothelial cells and human cerebral small vessel disease. Brain Pathol. 2015;25(1):44-50.

138. Hassan A, Hunt BJ, O'Sullivan M, Bell R, D'Souza R, Jeffery S, et al. Homocysteine is a risk factor for cerebral small vessel disease, acting via endothelial dysfunction. Brain. 2004;127(Pt 1):212-9.

139. Pavlovic AM, Pekmezovic T, Obrenovic R, Novakovic I, Tomic G, Mijajlovic M, et al. Increased total homocysteine level is associated with clinical status and severity of white matter changes in symptomatic patients with subcortical small vessel disease. Clin Neurol Neurosurg. 2011;113(9):711-5.

140. Hainsworth AH, Yeo NE, Weekman EM, Wilcock DM. Homocysteine, hyperhomocysteinemia and vascular contributions to cognitive impairment and dementia (VCID). Biochim Biophys Acta. 2016;1862(5):1008-17.

141. Kondziella D, Gothlin M, Fu M, Zetterberg H, Wallin A. B-type natriuretic peptide plasma levels are elevated in subcortical vascular dementia. Neuroreport. 2009;20(9):825-7.

142. Mirza SS, de Bruijn RF, Koudstaal PJ, van den Meiracker AH, Franco OH, Hofman A, et al. The N-terminal pro B-type natriuretic peptide, and risk of dementia and cognitive decline: a 10-years follow-up study in the general population. J Neurol Neurosurg Psychiatry. 2016;87(4):356-62.

143. Schneider AL, Rawlings AM, Sharrett AR, Alonso A, Mosley TH, Hoogeveen $\mathrm{RC}$, et al. High-sensitivity cardiac troponin $\mathrm{T}$ and cognitive function and dementia risk: the atherosclerosis risk in communities study. Eur Heart J. 2014;35(27):1817-24

144. Pikula A, Boger RH, Beiser AS, Maas R, DeCarli C, Schwedhelm E, et al. Association of plasma ADMA levels with MRI markers of vascular brain injury: Framingham offspring study. Stroke. 2009;40(9):2959-64.

145. Tsai NW, Chang YT, Huang CR, Lin YJ, Lin WC, Cheng BC, et al. Association between oxidative stress and outcome in different subtypes of acute ischemic stroke. Biomed Res Int. 2014;2014:256879.

146. Wallin A, Ohrfelt A, Bjerke M. Characteristic clinical presentation and CSF biomarker pattern in cerebral small vessel disease. J Neurol Sci. 2012;322(1-2, 192):-16.

147. Blennow K, Wallin A, Fredman P, Karlsson I, Gottfries CG, Svennerholm L. Blood-brain barrier disturbance in patients with Alzheimer's disease is related to vascular factors. Acta Neurol Scand. 1990;81(4):323-6.
148. Frolich L, Kornhuber J, Ihl R, Fritze J, Maurer K, Riederer P. Integrity of the blood-CSF barrier in dementia of Alzheimer type: CSF/serum ratios of albumin and lgG. Eur Arch Psychiatry Clin Neurosci. 1991;240(6):363-6.

149. Mroczko B, Groblewska M, Zboch M, Kulczynska A, Koper OM, Szmitkowski $M$, et al. Concentrations of matrix metalloproteinases and their tissue inhibitors in the cerebrospinal fluid of patients with Alzheimer's disease. J Alzheimers Dis. 2014;40(2):351-7.

150. Horstmann S, Budig L, Gardner H, Koziol J, Deuschle M, Schilling C, et al. Matrix metalloproteinases in peripheral blood and cerebrospinal fluid in patients with Alzheimer's disease. Int Psychogeriatr. 2010;22(6):966-72.

151. Peskind ER, Griffin WS, Akama KT, Raskind MA, Van Eldik LJ. Cerebrospinal fluid S100B is elevated in the earlier stages of Alzheimer's disease. Neurochem Int. 2001;39(5-6):409-13.

152. Petzold A, Jenkins R, Watt HC, Green AJ, Thompson EJ, Keir G, et al. Cerebrospinal fluid S100B correlates with brain atrophy in Alzheimer's disease. Neurosci Lett. 2003;336(3):167-70.

153. Craig-Schapiro R, Perrin RJ, Roe CM, Xiong C, Carter D, Cairns NJ, et al. YKL40: a novel prognostic fluid biomarker for preclinical Alzheimer's disease. Biol Psychiatry. 2010;68(10):903-12.

154. Huang CW, Tsai MH, Chen NC, Chen WH, Lu YT, Lui CC, et al. Clinical significance of circulating vascular cell adhesion molecule- 1 to white matter disintegrity in Alzheimer's dementia. Thromb Haemost. 2015:114(6):1230-40.

155. Gubandru M, Margina D, Tsitsimpikou C, Goutzourelas N, Tsarouhas K, Ilie M, et al. Alzheimer's disease treated patients showed different patterns for oxidative stress and inflammation markers. Food Chem Toxicol. 2013;61: 209-14

156. Rosenberg GA, Wallin A, Wardlaw JM, Markus HS, Montaner J, Wolfson L, et al. Consensus statement for diagnosis of subcortical small vessel disease. J Cereb Blood Flow Metab. 2016;36(1):6-25.

157. Ravid R. The uniqueness of biobanks for neurological and psychiatric diseases: potentials and pitfalls. Pathobiology. 2014;81(5-6):237-44.

\section{Submit your next manuscript to BioMed Central and we will help you at every step:}

- We accept pre-submission inquiries

- Our selector tool helps you to find the most relevant journal

- We provide round the clock customer support

- Convenient online submission

- Thorough peer review

- Inclusion in PubMed and all major indexing services

- Maximum visibility for your research

Submit your manuscript at www.biomedcentral.com/submit

Biomed Central 